ORDINES MILITARES

COLLOQUIA TORUNENSIA HISTORICA

Yearbook for the Study of the Military Orders

ISSN (print) 0867-2008 / ISSN (online) 2391-7512

DOI: http://dx.doi.org/10.12775/OM.2016.005

LIBOR JAN

Historický ústav

Filozofická fakulta

Masarykova univerzita

Gorkého 63/ I 4

CZ-6o2 oo Brno

Czech Republik

jan@phil.muni.cz

\title{
ZUM SCHICKSAL DER GÜTER DER GEISTLICHEN RITTERORDEN IN BÖHMEN UND MÄHREN NACH DEN HUSSITENKRIEGEN
}

\section{KeYwORDS}

economical history; Military-Religious Orders; relations between kings and Military-Religious Orders; sequestration of orders'properties, Teutonic Order, Hospitallers, Bohemia and Moravia in the Isth century

A m I. Mai 1459 schrieb der Landkomtur für Böhmen und Mähren Wilhelm von Schönburg an den Hochmeister des Deutschen Ordens Ludwig von Erlichshausen ein Schreiben reich an traurigen Nachrichten. Es ging um die Lage der Ordensgüter in den beiden Ländern. In den vorangegangenen fünfzig Jahren hatten die früher umfang- und ertragreichen Güter des Deutschen Ordens in Böhmen und Mähren verschiedene Schicksalsschläge hinnehmen müssen, die faktisch eine Liquidierung der einst prosperierenden Ballei bedeuteten, welche seit den zoer Jahren des I4. Jahrhunderts zu den Kammerballeien des Hochmeisters gehörte. Das Ordenshaus in Komotau (tsch. Chomutov) mit seinen Zugehörigkeiten (Kometaw das hauss und dy czugehorunge) hatte laut dem Landkomtur ein gewisser Calta (Czaltha) für 5000 Schock Groschen gekauft, jedoch mit dem Zusatz, dass der Hochmeister noch zustimmen musste. Als Verkaufsgrund wurde angeführt, der Orden könne es sich nicht leisten, bei der Pfarrei

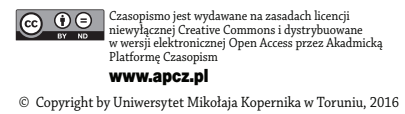


Komotau mehr als zwei oder drei Priester zu unterhalten. In Drobowitz (Trogawicz, tsch. Drobovice), wo nach Wilhelm der Hochmeister Hermann von Salza begraben liegt, ${ }^{48}$ sei die Kirche bis auf den Grund zerstört und dasselbige guth für 4000 Schock Groschen dem Ritter Jetřich (Dietrich) Chlumecký (Yetrzych Klumetzky) übertragen worden, dessen Absichten nicht bekannt seien. Diese Verpfändung habe bereits Kaiser Sigismund durchgeführt. Austerlitz (tsch. Slavkov) in Mähren, und zwar Burg und Stadt (eyn sloss und eyne stat das ist genanth Nawsterlicz), sei gegen 3000 Schock Groschen dem Herrn Johann von Černá Hora verpfändet, und die kleine Stadt Miletein (tsch. Miletín) mit dem Hof (eyn stetelen das heisst Militin und des ordens hof) unweit von Königgrätz sei im Wert von 800 Schock Groschen verpfändet worden. In Böhmen halte, so der Landkomtur, der Orden Häuser in Pilsen, Komotau (und zwar allein die dortige Pfarrei) und Bilin (tsch. Bílina). Den besten Ordensbesitz stelle die Kommende Neuhaus (tsch. Jindřichův Hradec) dar, die ihre Stifter, die Herren von Neuhaus, beschützt hätten. Weitere Pfarreien und Höfe in Böhmen seien von den Wyclifisten, d. h. von den Hussiten, besetzt: St.-Benedikt in Prag, dessen Kirche völlig zerstört sei, Aussig an der Elbe (tsch. Ústí nad Labem), wo die Kirche noch stehe, Königstein, Lobositz (tsch. Lovosice), Pitschkowitz (tsch. Býčkovice), Kolin (tsch. Kolín), Časlau (tsch. Čáslav), Deutschbrod (tsch. Německý Brod, geg. Havlíčkův Brod), Polna (tsch. Polná), ferner in Mähren Mährisch Kromau (tsch. Moravský Krum-

48 Dabei handelte es sich nicht um den Hochmeister Hermann von Salza, sondern um den Hochmeister Konrad von Feuchtwangen, der Anfang Juli 1296 in Prag starb und wirklich in Drobowitz begraben wurde, damals der Hauptkommende des Ordens in Böhmen, vgl. Di Kronike von Pruzinlant des Nicolaus von Jeroschin, hrsg. v. E. Strehlke (Scriptores rerum Prussicarum I), Leipzig 1861, S. 543: [...] und schît darnach kegn Prage, / da ouch des todis vlage / vorschrît sin aldin tage / unde im sundir clage / ein andir bezzir lebin gab, / daz da hat aldir ane stab, / wernde sterke ane lab. / Zu Drogewitz da ist sin grab; U. NIESS, Konrad von Feuchtwangen, in: Die Hochmeister des Deutschen Ordens 1190-1994, hrsg. v. U. Arnold (Quellen und Studien zur Geschichte des Deutschen Ordens 40), Marburg 1998, S. 43-44. Zum Datum von Konrads Tod (nach verschiedenen Quellen 2.-5. Juli) siehe U. Arnold, Konrad von Feuchtwangen, in: ders., Zakon krzyżacki z Ziemi Świętej nad Battyk, Toruň 1996, S. 85, 88-89, und Anm. 164 auf S. 100. Die Ähnlichkeit des Namens Drobowitz in den lateinischen Quellen (Trobowicz, Trebowitz usw.) mit dem Namen des schlesischen Trzebnica (Trebnicz, Trebonitz) ließ die humanistische Sage über die Beerdigung des Hochmeisters in der Trebnitzer Klosterkirche entstehen. Im 17. Jahrhundert wurde dort sogar ein Grabstein aus rotem Marmor angefertigt. Die jüngere Geschichtsschreibung wollte dies als Übertragung sterblicher Reste des Hochmeisters in hussitischen Zeiten erklären (vgl. Niess (wie oben), S. 43; Arnold (wie oben), S. 89). Der obige Brief des Landkomturs Wilhelm von Schönburg beweist, dass man noch nach der Mitte des 15. Jahrhunderts im Ordensmilieu von dem Grab in Drobowitz wusste, es jedoch Konrads Vorgänger Hermann von Salza zuschrieb. Die Annahme einer Translation des Hochmeisters aus Drobowitz nach Trebnitz im Zusammenhang mit den Hussitenkriegen oder in der Zeit danach lässt sich deshalb ausschließen. 
lov) und Ossowa Bittischka (tsch. Osová Bitýška, mittelhochdeutsch Vitis). Dem Landkomtur unterständen weiterhin auch die Kommenden in Troppau (tsch. Opava) und in Jägerndorf (tsch. Krnov). Diese seien aber mit hohen Schulden belastet und müssten ihre Güter wie auch ihre Stadtzinsen verkaufen. In Mähren verfüge Wilhelm von Schönburg immer noch über die Kommende in Hosterlitz (tsch. Hosterradice) und die Pfarren in Austerlitz, Krenowitz (tsch. Křenovice), Deblin (tsch. Deblín), Hrottowitz (tsch. Hrotovice, mittelhochdeutsch Rutwicz) und Tropplowitz (tsch. Opavice). Im Schlussteil seines Schriftstücks äußerte der Landkomtur vorsichtig Hoffnung auf Hilfe durch König Georg von Podiebrad, um die erwähnten Pfarreien und Güter, vor allem Komotau, Austerlitz, Drobowitz und Miletein, für den Orden zurückzugewinnen, denn der Orden selbst sei viel zu schwach, um sie auszulösen. ${ }^{49}$

Der Niedergang des Ordensgutes hatte aber nicht nur seine Geschichte, in der verwüstenden Haufen hussitischer "Gotteskämpfer" und dem verzweifelten Bemühen Sigismunds um finanzielle Mittel, sondern auch seine Vorgeschichte, deren Hauptfiguren Herzog Přemek von Troppau, der mährische Markgraf Jodok und schließlich der böhmische und römische König Wenzel IV. waren. Wohl in der zweiten Phase des Kampfes mit seinem Bruder Prokop ließ Markgraf Jodok bereits 1393 eine der bedeutendsten Ordenskommenden im Lande, nämlich Austerlitz, besetzen. Das Gut wurde dem Orden, höchstwahrscheinlich im völlig verwüsteten Zustand, anscheinend erst 1406 zurückgegeben..$^{\circ \circ}$ In der zweiten Hälfte des Jahres 1394 dürfte der Troppauer Herzog Přemek die Ordenskommende in Troppau überfallen und sie wie auch ihre Befestigung und die Mühle niedergerissen haben. Dabei wurden der Ordenskomtur und der Pfarrer Wenzel aus Deutschbrod mit den Brüdern vertrieben und drei Dörfer des Ordens bei Leobschütz (poln. Głubczyce) besetzt. Der Orden beklagte sich in Rom und der Abt des Schottenklosters in Wien Heinrich entschied am 26. Juli I398, Přemek müsse dem Orden den Schaden ersetzen. Die Verhandlungen mit dem Herzog zogen sich aber in die Länge. Im Jahre 1402 hatte zwar der Orden die Kommende wieder in seinem Besitz, der Herzog aber war den Ordensrittern nach acht Jahren einbehaltener Löhne immer noch 520 Schock und 40 Groschen schuldig. Ferner

49 M. Millauer, Der deutsche Ritterorden in Böhmen. Ein Beitrag zur Reichs-und Kirchengeschichte Böhmens, Praga 1832, S. 187-190; Fontes rerum Austriacarum, II. Abth. Diplomataria et Acta, Bd. XX: Urkundliche Beiträge zur Geschichte Böhmens und seiner Nachbarländer im Zeitalter Georg's von Podiebrad (1450-1471), Wien 1860, S. 81-82; J. Voigt, Geschichte der Ballei des Deutschen Ordens in Böhmen (Denkschriften der kaiserlichen Akademie der Wissenschaften, Phil.-hist. Klasse 12), Wien 1862, S. 136-137.

50 L. Jan, Zkáza českomoravské bailie rádu némeckých rytî́rú, Časopis Matice moravské 117 (1998), S. 386 . 
musste der Landkomtur Albrecht von Dauba weitere 252 Gulden für den in Rom geführten Rechtsstreit ausgeben. ${ }^{\text {s }}$

Wegen ihres wirtschaftlichen Potentials sowie ihrer strategischen Lage wollte zudem König Wenzel die Komotauer Kommende mit der Stadt und mehr als 30 Dörfern dem Orden wegnehmen. Darüber wurde der Hochmeister Konrad von Jungingen informiert, und es gelang schließlich, die Besetzung zu verhindern..$^{52}$ In der Woche vor Pfingsten ( I I.-1 7. Mai) I 404 befahl König Wenzel, die Ordensburg Platten (tsch. Blatno) zwei seiner Amtsträger übergeben, dem Burggrafen von Brüx Peter Milíčovec und dem Hauptmann in Dux Heincze von Kauffung. Die Burg Platten gehörte ursprünglich in den Bezirk der Komotauer Kommende. ${ }^{53}$ Im Jahre 1403 wurde dort jedoch eine Sonderkomturei für den ehemaligen Landkomtur Albrecht von Dauba errichtet, der mit dem Komotauer Gesinde und den dortigen Bürgern Kriegseinfälle ins benachbarte Meißen unternahm. Dank persönlichem Engagements gelang es dem Landkomtur Ulrich von Ausk (tsch. Ústí, heute Sezimovo Ústí), die Aufgabe der Burg abzuwenden. ${ }^{54}$

Das Vorgehen aller drei Fürsten hatte in allen angegebenen Fällen politische und vielleicht auch strategische Ursachen. Der Orden wehrte sich mit Hilfe der kirchlichen Justiz nur im Falle von Troppau, wo direkte Gewalt angewendet worden war. Bei der Beschlagnahme von Austerlitz stützte sich Markgraf Jodok zweifellos auf sein sogenanntes Stifterrecht, das mit Sicherheit im Einklang mit dem böhmischen und mährischen Landrecht stand. Diese Rechte gaben dem Stifter oder seinem Rechtsnachfolger die Befugnis, auf die materielle Ausstattung ihrer Stiftung zurückzugreifen, falls es nötig war. Auch wenn unlängst der polnische Forscher M. R. Pauk den mehrere Jahrzehnte lang im tschechischen mediävistischen Diskurs üblichen Begriff „Stifterrecht“ infrage mit dem Hinweis stellte, es handele sich um ein gewöhnliches Patronat (ius patronatus), ss wird nachfolgend

51 HStA Dresden, Ältere Urkunden, Nr. 5063; vgl. Jan, Zkáza (wie Anm. 3), S. 385-386.

52 Voigt (wie Anm. 2), S. 103; J. Hemmerle, Die Deutschordens-Ballei Böhmen in ihren Rechnungsbüchern 1382-1441 (Quellen und Studien zur Geschichte des Deutschen Ordens 22), Bonn 1967, S. 26; Jan, Zkáza (wie Anm. 3), S. 385; L. Jan, King Wenceslas and the Dissolution of the Bohemian Bailiwick of the Teutonic Knights, in: Mendicants, Military Orders and Regionalism in Medieval Europe, ed. J. Sarnowsky, Aldershot 1999, S. 235.

53 L. Jurošková, Hospodár ské strategie českomoravské bailie rádu nèmeckých rytîrư. Př́klad chomutovské komendy (Ústecký sborník historický 2004; Gotické umění a jeho historické souvislosti III), Ústí nad Labem 2004, S. 135.

54 Hemmerle (wie Anm. 5), S. 27-28; weiter Nr. 166; Voigt (wie Anm. 2) S. 111-113; Jurošková (wie Anm. 6), S. 151.

55 M. R. Pauk, Dziatalność fundacyjna możnowladztwa czeskiego i jej uwarunkowania spoteczne (XI-XIII wiek), Kraków-Warszawa 2000, S. 223-230; ders., Klasztor jako zaplecze ekonomiczne wtadzy królewskiej w państwie ostatnich Przemyślidów, in: Klasztor w państwie średniowiecznym 
versucht zu zeigen, dass für beide Länder weiterhin das Stifterrecht als ein relevanter Faktor in der Diskussion zu gelten hat. Von diesen Stifterrecht leitete sich nämlich die Verpflichtung ab, die allgemeine Steuer (berna generalis) sowie die Sondersteuer (berna specialis) zu zahlen, welche pflichtgemäß auch die vom Landesherren gegründeten Städte leisten mussten. Die zweite Steuerart verfestigte sich im Laufe des I 3. und I 4. Jahrhunderts zu einer regelmäßigen Abgabe. Spätestens unter Karl IV., wahrscheinlich aber schon früher, wurde sie alljährlich abgeführt. In der Zeit Wenzels IV. wurde manchmal das Eineinhalb- oder gar das Zweifache des Normalbetrags in einem Jahr eingefordert. So befahl im Jahre I 403 Sigismund von Luxemburg als Landesverwalter, während der Wiener Gefangenschaft seines Bruders Wenzel, von Klöstern und Städten die Landessteuer in zweifacher Höhe einzunehmen. Das gleiche tat dann Wenzel IV. selbst, als er aus seiner Gefangenschaft zurückgekehrt war. Insgesamt mussten also die geistlichen Institutionen und die Städte in einem einzigen Jahr das Vierfache der gewöhnlichen jährlichen Summe bezahlen, die im böhmischen Teil der böhmisch-mährischen Ballei 200 Schock Prager Groschen betrug (und bei den Johannitern 330 Schock Groschen). Solche Steuerpolitik bedeutete für viele Ordenshäuser in der Tat die Liquidierung. Um die nötige Summe zu beschaffen, musste der Landkomtur die Kommende Miletein dem Anhänger des Königs und hohen Würdenträger Johann Krušina von Lichtenburg auf seine Lebenszeit für 700 Schock Groschen verkaufen. ${ }^{66}$ Nach dem Tod des Johann Krušina verkaufte der Landkomtur Ulrich von Ausk am 5. Februar I 4 I O das verschuldete Miletein dem Meister der königlichen Kammer Beneš von Chussnyk (tsch. Choustník) und seiner Frau auf Lebenszeit für 850 Schock Groschen und die Pflicht, jedes Jahr dem Ordenspfarrer den Betrag von Io Schock Groschen auszuzahlen. ${ }^{57}$

Aus den gleichen Gründen wurde im Frühjahr I 409 Herso (tsch. Hereš) von Wruttitz (tsch. Kropáčova Vrutice) auf sechs Jahre für einen Jahreszins von 70 Schock Groschen, den Lebensunterhalt eines Ordenspriesters und die Aufrechterhaltung der dortigen Kirche die prosperierende Kommende Pitschkowitz im Leitmeritzer Kreis verpfändet, die zuvor gemeinsam mit Komotau direkt der

i nowożtnym, red. M. Derwich, A. Pobóg-Lenartowicz, Wrocław-Opole-Warszawa 2005, S. 225-240, hier auf S. 237-239.

56 Hemmerle (wie Anm. 5), Nr. 139, 165; M. Čapský, Miletinská komenda rádu némeckých rytîrư $v$ dobè predhusitské ve svètle účetnich pramenư, in: Celostátni studentská védecká konference Historie 1997, Brno 1998, S. 23-24.

57 Millauer (wie Anm. 2), S. 175-182; Voigt (wie Anm. 2), S. 120; Čapský (wie Anm. 9), S. 23-25; Jan, King Wenceslas (wie Anm. 5), S. 239. 
Landkomtur Ulrich von Ausk verwaltet hatte. Der König stimmte dieser Transaktion am 30. Mai des gleichen Jahres zu. ${ }^{58}$

Die eigentliche Katastrophe für den Deutschordensbesitz kam aber erst nach der Schlacht bei Tannenberg I 4 IO. Der Orden konnte nicht nur seine bestehenden Schulden gegenüber dem König Wenzel (ein Teil wurde im Jahre I 4 I I beglichen) nicht bezahlen, sondern versuchte sogar, vermittelt durch Albrecht von Dauba und Ulrich von Ausk, ein weiteres Darlehen zu erhalten.99 Darauf wollte sich der König jedoch keineswegs einlassen und seine ungünstige finanzielle Lage führte ihn zur direkten Beschlagnahmung der größten und ertragreichsten Ordenskommenden. So übernahm schon am 6. März I 4 I I , nicht lange nach dem Tod des Markgrafen Jodok, ein Gläubiger des Königs, Wenzel Hase aus Brünn, aus den Händen des Komturs Konrad von Czachwitz Austerlitz, die bedeutendste mährische Kommende. Am 20. September übergab der Landkomtur zwei Bevollmächtigten, von denen einer der Mundschenk des Königs Dietrich Kraa war, Drobowitz. Und am nächsten Tag, dem 2r. September, übernahm ein weiterer Vertrauensmann des Königs, Stephan von Kobershain, der wahrscheinlich der Harnischmeister des Königs war, vom Provinzial Ulrich von Ausk Komotau. ${ }^{60}$ Wohl kurz darauf besetzte Stephan von Kobershain die Burg Platten, denn für die dortige Kirche präsentierte er als Komotauer Burggraf am 6. April I 4 I 2 einen Pleban. ${ }^{61}$

Gefragt werden muss nach dem weiteren Schicksal von Komotau, das im Laufe des I 4. Jahrhunderts (oder eher in dessen zweiter Hälfte) zur bedeutendsten und im Prinzip ertragsreichsten Ordensherrschaft, dank zielstrebiger Bemühungen mehrerer (nicht aller) Landkomture die Güter zu zentralisieren, weitere dazuzugewinnen und den Betrieb möglichst effektiv zu gestalten, geworden war. Die Zeit der Hussitenkriege brachte hier einen grundlegenden Wandel. König Sigismund, der sein böhmisch-mährisches Erbe erkämpfen wollte, brauchte hohe Geldsummen für die Begleichung des Soldes und des Kostenaufwands seiner adeligen Verbündeten. Wahrscheinlich aus diesem Grund verpfändete er schon kurz nach dem Ableben seines Bruders Wenzel († I6. August I419) Komotau

58 Hemmerle (wie Anm. 5), Nr. 392, 420; Voigt (wie Anm. 2), S. 120, Edition des Reverses des Hersso von Wruttitz auf S. 143-146 (č. VII), Edition der königlichen Bewilligung auf S. 146 (č. VIII); vgl. auch Jan, Zkáza (wie Anm. 3), S. 388; Jan, King Wenceslas (wie Anm. 5), S. 239.

59 Dazu vgl. M. Čapský, Fiskálni vazby českomoravské bailie a velmistrovské komory rádu némeckých rytîrư, Sborník prací filozofické fakulty brněnské univerzity / Studia historica Facultatis philosophicae Universitatis Brunensis C 46 (1999), S. 74-75.

60 Hemmerle (wie Anm. 5), Nr. 409-417.

61 Libri confirmationum ad beneficia ecclesiastica Pragensem per archidiocesim (weiter: LC), Bd. VII, ed. J. Emler, Pragae 1886, S. 50. 
(Kompthow) seinem Anhänger Bodo von Eulenburg, was dem Bericht des Ordensbruders und in Italien graduierten Doktors der Dekrete Jost Quedenaw an den Hochmeister Michael Küchmeister vom I I. März I 420 zu entnehmen ist. ${ }^{62}$ Noch im gleichen Jahr, und zwar am 29. Juni ,auf dem Feld vor Prag", übergab dann Wilhelm von Hasenburg den Besitz Komotaus dem neuen Inhaber bis zur Auszahlung 3000 Schock Groschen. ${ }^{63}$ Eine echte Katastrophe traf den Güterkomplex aber erst im Frühjahr I 42 I. Am Palmsonntag (16. März) wurde Komotau von einem taboritischen Heer, das Johann Žižka anführte, und von den Pragern nach einer nur eintägigen Belagerung erobert. Die deutschen Bürger, von denen manche zweifelsohne die Kriegszüge Albrechts von Dauba oder Johanns von Egerberg ins benachbarte Meißen in Erinnerung hatten, hatten sich tapfer verteidigt und den Angriff mit Hilfe erhitzten Harzes und kochenden Wassers abzuschlagen versucht. Dessen ungeachtet wurde die Stadt erobert, ihre Einwohner wurden übel massakriert; nur dreißig ließ man am Leben, damit die Opfer beerdigt werden konnten. Die anwesenden Adeligen aus der Gegend, manche Bürger, die Geistlichkeit und die Juden wurden verbrannt. Im niederträchtigen Verhalten zeichneten sich vor allem die taboritischen Frauen aus, welche Frauen und Mädchen aus der Stadt hinauslockten, wo die nichts ahnenden Opfer beraubt und in einer Weinbude verbrannt wurden, wie der Chronist Laurentius von Březová berichtet. Ihm zufolge wurden in der Stadt um zweitausend Menschen totgeschlagen, die sogenannten Alten Annalen von Böhmen schätzen die Zahl der Opfer sogar auf 2400. „Der Alte Kollegiat“ berichtet, dass ein Teil der Männer totgeschlagen und ein anderer verbrannt wurde, viele Frauen und die Juden mit ihren Frauen und Kindern warfen sich freiwillig ins Feuer, nachdem sie angeblich davor ohne Zweifel unter Anwendung von Gewalt getauft worden waren. ${ }^{64}$ Mit einem Feind, der sich

62 Regesta historico-diplomatica Ordinis S. Mariae Theutonicorum 1198-1515, bearb. v. E. Joachim, hrsg v. W. Hubatsch, Bd. I, Göttingen 1948, S. 196, Nr. 3119; Voigt, Geschichte (wie Anm. 2), S. 126, haben fälschlich Jahr 1414, ähnlich K. Beránek, V. Beránková, Část archivu chomutovské komendy rádu nèmeckých rytirư ve Státnim ústredním archivu v Praze, in: Facta probant homines. Sbornik príspèvkủ k životnimu jubileu prof. Dr. Zdeňky Hledikové, hrsg. I. Hlaváček, J. Hrdina, u. Mitwirkung v. J. Kahuda, E. Doležalová, Praha 1998, S. 49, auch wenn in Anm. 10 auf der selbe Seite führen die rechte Datierung des Quedenaws Briefes.

${ }^{63}$ Archiv český (weiter: AČ), Bd. II, S. 192, Nr. 352; A. Sedláček, Zbytky register králiov řimských a čských z let 1361-1480 (Historický archiv 39), Praha 1915, S. 151, Nr. 1048.

64 Aus den Quellen spricht über das Ereignis Die hussitische Chronik des Laurencius von Březová: Vavrince z Březové Kronika husitská, ed. J. Goll, Fontes rerum Bohemicarum, Bd. V, Praha 1893, S. 476-477; Staré letopisy české (texty nejstarši vrstvy), ed. A. M. Černá, P. Čornej, M. Klosová, Fontes rerum Bohemicarum, Series nova, Bd. I, Praha 2003, S. 20-21; Kronika starého kollegiata Pražského. Chronicon veteris collegiati Pragensis, ed. J. Emler, Fontes rerum Bohemicarum, Bd. VII (Korrekturenabzug des nichtherausgebenen Bandes VI), Praha s. d., S. 28. In breiterem 
zur Wehr setzte, rechneten die Hussiten unbarmherzig ab, die Stadt wurde faktisch entvölkert und ihr Wiederaufbau nahm lange Zeit in Anspruch, wie noch aus der Urkunde König Georgs von Podiebrad abzulesen ist, mit welcher er am i 8. April I 466 die Führung der Stadtbücher und ferner den Besitz neu besiedelter Liegenschaften und Grundstücke bewilligte. ${ }^{65}$ In dieser Urkunde wird aber zugleich behauptet, dass ein Teil der Stadtbewohner geflüchtet sei. Auch wenn Chronisten nicht immer zuverlässige Opferzahlen angeben, handelte es sich doch zweifelsohne um ein großes Blutvergießen.

Die Prager Besatzung hat anschließend Komotau und ebenso die nahe Stadt Kaaden (tsch. Kadaň) für mehrere Monate beherrscht. Als sich aber in der Oktav von Mariä Geburt (8.- I 5. September) I 42 I das meißnische Heer mit dem Markgrafen Friedrich an der Spitze und Truppen mancher böhmischer katholischer Herren näherte, befahlen die Hauptleute beider Städte, Teile des Mauerrings niederzureißen und Häuser in Brand zu setzen. Danach zogen sie mit ihren Besatzungen nach Saaz (tsch. Žatec) und in andere Orte ab. Die Meißner haben Komotau und Kaaden besetzt und begannen, Bilin zu erobern. Diese Belagerung gaben sie aber auf, als sie die Nachricht von dem sich nähernden Prager Heer erhielten. ${ }^{66}$ Der Markgraf behielt allerdings Komotau und übergab es den Brüdern Anarg und Heinrich von Waldenburg, Herren auf Wolkenstein, was einem Schriftstück zu entnehmen ist, das beide Brüder am 26. Mai I 425 ausstellten. Sie baten darin den Abt und Archidiakon Ortwin aus Chemnitz um Fürsprache bei dem römischen König Sigismund, falls dieser ihnen Komotau wegnehmen wollte, denn sie hätten die Stadt drei Jahre lang besessen, nachdem der sächsische Herzog (Friedrich) und sein Bruder Markgraf Wilhelm daraus die Ketzer vertrieben hatten; dadurch seien ihnen erhebliche Kosten und Schäden entstanden. Der Abt sollte ihnen zu einer Entschädigung seitens des römischen Königs verhelfen ${ }^{67} \mathrm{Kö-}$ nig Sigismund verpfändete in der Tat bereits am 6. Januar 1424 Komotau und Platten um 4000 Schock Groschen dem Hauptmann des Saazer Landfriedens Nikolaus dem „Armen“ von Lobkowitz. Schließlich verpfändete Sigismund am 23. November I 437 Komotau mésto a klášter krížovnikiov Pruských („die Stadt und das Kloster der preußischer Kreuzherren“) mit weiterem Kirchengut, darun-

Zusammenhang F. Šmahel, Die Hussitische Revolution, Bd. II (Monumenta Germaniae Historica, Schriften 43), Hannover 2002, S. 1145-1146.

65 Codex iuris municipalis regni Bohemiae. Privilegia regalium civitatum provincialium annorum 1420-1526, ed. J. Čelakovský, G. Friedrich, Praha 1948, S. 492-493, Nr. 284.

66 Vavrince z Březové Kronika (wie Anm. 17), S. 511; vgl. Šmahel, Die Hussitische Revolution (wie Anm. 17), S. 1207-1208.

67 Codex diplomaticus Saxoniae regiae, Bd. II 6 (Urkundenbuch des Stadt Chemnitz und ihrer Klöster), ed. H. Ermisch, Leipzig 1879, Nr. 394, S. 358-359. 
ter Ploschkowitz (tsch. Ploskovice), welches die Johanniter hielten, in der Summe 5000 Schock Groschen dem ehemaligen hussitischen Hauptmann Jakoubek von Vŕesovice. ${ }^{68}$ In die Hände der Hussiten kam die Stadt wahrscheinlich nach der Schlacht bei Aussig an der Elbe (16. Juni I 426) und im Jahre I 427 wurde Jakoubek, der Hauptmann des Städtebundes von Saaz und Laun, auch als Hauptmann in Komotau bezeichnet. ${ }^{69}$ Noch am 27. April 1452 wurde als Besitzer von Komotau Jakoubeks Sohn Johann von Vresovice genannt. ${ }^{70}$

$\mathrm{Zu}$ weiteren Änderungen kam es I 454, als am 3. September König Ladislaus Posthumus Nikolaus von Lobkowitz, dem Sohn des vorherigen Pfandinhabers, den Verpfändungsbrief auf Komotau und die Burg Platten bestätigte (civitatis nostre Chomutaw cum Castro Platen ac villis et universis [...] pertinenciis), als König Sigismund dessen Vater über 4000 Schock Groschen ausgestellt hatte. Zudem verschrieb König Ladislaus Nikolaus von Lobkowitz weitere ı 000 Schock Groschen für die Auslösung von Kaaden bei Heinrich von Plauen, die Nikolaus dann dem König zurückerstattete. Der Herrscher konnte Komotau und Platten gegen 5000 Schock Groschen nach jährlicher Kündigungsfrist auslösen. ${ }^{71}$ Gleich am 1 3. Januar 1455 jedoch übergab König Ladislaus in Breslau seinem Kämmerer Johann Calta von Kamenná Hora für seine Dienste die Stadt Komotau, die Burg Platten, alles mit Zubehör und dazu den Hof Pitschkowitz (dwuor Biczkowicze) ${ }^{72}$ ebenfalls mit allen Zugehörigkeiten als freien allodialen Erbbesitz. Am i I. Februar 1457 übertrug der König Johann Calta den Pfandbesitz von Komotau und

68 Sedláček (wie Anm. 16), Nr. 859, S. 22; Nr. 1407, S. 193-194; AČ I, S. 495, Nr. 6; AČ II, S. 452-453, Nr. 539.

69 P. Rak, Chomutov 1252-2002. Vybraná data ze 750 let historie města, Chomutov 2002, S. 16.

70 Ebd.

71 Národní archiv (weiter: NA) Praha, fond České gubernium - Guberniální listiny (weiter: ČG GL) Nr. 279; Beránek, Beránková (wie Anm. 15), S. 58, Nr. 19.

72 Wie schon erwähnt, musste der Orden Pitschkowitz bei Leitmeritz am 4. April 1409 auf sechs Jahre unter genau festgesetzten Bedingungen an Herso von Wrutitz übergeben. Die weitere Schicksale der ehemaligen Kommende sind unklar. Nach der erwähnten Relation des Jost Quedenaw hielt Pischkowitz (Pyeswick) im Frühling 1420 „Herr Joersig“, vielleicht Georg von Dauba, Herr auf Weissenburg (Regesta historico-diplomatica (wie Anm. 15), Bd. I, S. 196, Nr. 3119). 1422 verpfändete das Gut um 2000 Schock Groschen König Sigismund gemeinsam mit Leitmeritz sowie den Burgen Kalich und Panna an Sigismund von Wartenberg auf Tetschen (tsch. Děčín; Sedláček (wie Anm. 16), S. 125, Nr. 890; AČ I, S. 545, Nr. 270). Sigismund verpfändete dann am 4. März 1437 Pitschkowitz mit sechs Dörfern und anderen Vermögen geistlicher Institutionen an Henig von Waldstein um 500 Schock Groschen (Sedláček (wie Anm. 16), S. 200, Nr. 1457; AČ I, S. 505, Nr. 57). König Ladislaus verschrieb 1456 die Veste Pitschkowitz mit drei Dörfern an Wenzel Carda von Petrovice und Johann von Tetčiněves (Sedláček (wie Anm. 16), S. 234, Nr. 1687). In den Jahren 1418, 1422 und 1423 präsentierte die Pfarrer in Pitschkowitz aber immer noch der Ordensprovinzial Albrecht von Dauba (LC VII, ed. J. Emler, Pragae 1886, S. 265; viii-x; Pragae 1889, S. 11, 56). 
Platten, denn Calta hatte, nun als oberster Münzmeister, beide Güter für 5000 Schock Groschen bei Nikolaus von Lobkowitz ausgelöst. ${ }^{73}$ Schließlich versprach König Ladislaus am 24. Februar desselben Jahres wieder in Ofen (ung. Buda) Johann Calta, dass er Komotau mit Platten und Zugehörigkeiten weder von ihm noch von seinen Kindern auslösen werde. Die Möglichkeit der Einlösung blieb bestehen, sollte aber erst die nachfolgenden Generationen treffen, also Nachkommen oder Rechtsnachfolger der Kinder von Johann Calta, der seine Laufbahn als bedeutender Kriegsunternehmer begonnen hatte. ${ }^{74}$ Die königlichen Verpfändungsurkunden auf Komotau und die Herrschaft Rabstein bestätigte dem Johann Calta am 6. August 1459 auch König Georg von Podiebrad. ${ }^{75}$ Es ist kaum daran zu zweifeln, dass der Wortlaut der zwei letztgenannten Urkunden und der früheren vom Januar I 455 einander widersprechen. Während früher der König Calta Komotau als Allod übertrug, damit er in die Landtafel eingetragen wurde, behandelten die folgenden Urkunden Komotau wieder als Pfandbesitz. Zu erklären ist dies wohl wie folgt: Nicht lange nach der Ausfertigung der Schenkungsurkunde begann Calta, unterstützt durch König Ladislaus und Markgraf Friedrich von Brandenburg, Verhandlungen mit dem Hochmeister, um seine Besitzrechte an der Stadt Komotau anerkennen zu lassen. ${ }^{7}$ Der Hochmeister zögerte freilich mit seiner Zustimmung, weshalb Calta anders vorgehen musste. Er löste darum die bestehende Verpfändung aus, ohne den theoretischen Anspruch des Ordens zu beeinträchtigen.

Den Schlusspunkt im Verhältnis von Komotau zum Deutschen Orden setzte erst der Vertrag zwischen dem Ordensmeister in Deutschland und in Italien Reinhard von Neipperg einerseits sowie dem Burggraf von Karlstein und obersten Münzmeister Benesch von Weitmühl andererseits, wie am I 3. April I 488 vom Landkomtur in Franken Melchior von Neuneck und den Komture Graf Georg von Henneberg in Mergentheim, Pankraz von Reinstein in Frankfurt und Hartmann von Stockheim in Horneck beurkundeten. Diesem Schriftstück zufolge hatten der Deutschmeister und Benesch, der Schwiegersohn und Erbe des Johann Calta von Kamenná Hora, einen Vertrag über Komotau geschlossen, welches Benesch zu

73 NA Praha, ČG - GL, Nr. 287, 293; Beránek, Beránková (wie Anm. 15), S. 58, Nr. 20-21. Zum Johann Calta siehe U. Tresp, Jan Calta z Kamenné Hory. (Pozdnèstředověký válečnický podnikatel jako pán Chomutova), in: Comotovia 2005. Sbornik príspèvkủ z konference vènované výročí 400 let vykoupeni Chomutova $z$ poddanstvi (1605-2005), hrsg. v. P. Rak, Chomutov 2006, S. 27-36; ders., Söldner aus Böhmen. Im Dienst deutscher Fürsten: Kriegsgeschäft und Heeresorganisation im 15 Jahrhundert, Paderborn u. a. 2004 (Krieg in der Geschichte 19), S. 29-36.

74 NA Praha, ČG - GL, Nr. 294; Beránek, Beránková (wie Anm. 15), S. 58-59.

75 NA Praha, ČG - GL, Nr. 308; Beránek, Beránková (wie Anm. 15), S. 59.

76 Regesta historico-diplomatica (wie Anm. 15), Bd. I, Tl. 2, S. 3, Nr. 13453; S. 6, Nr. 13498; S. 8 , Nr. 13526; vgl. Beránek, Beránková (wie Anm. 15), S. 49-50. 
dieser Zeit besaß. Schon am 30. November I 487 waren die Komture in Virnsberg und Eger Diether von Stein und Georg Brüling sowie des Deutschmeisters Sekretär Herbort Tiel mit der Überschreibung der Ordensrechte auf Komotau in der Landtafel an Benesch beauftragt worden. ${ }^{77}$ Die Vollmacht des Deutschmeisters, mit der er die genannten Würdenträger beauftragte, wurde in deren Schriftstück inseriert und in der Tat auch in die alte Landtafel eingetragen, welche aber I 54 I verbrannte. Deswegen wurde sie erneut I 542 in die Landtafel eingetragen. Dort finden sich auch die böhmischen Aufzeichnungen, welche die Geschehnisse von I 488 beim Landtafelamt beschreiben. Die genannten Komture und der Sekretär traten am 2 I. Mai 1488 in der Tat vor die Beamten des Landgerichts und aussagten, dass Benesch von Weitmühl ihrem Orden die Entschädigung in Gold auszahlte. Im Namen des Deutschmeisters verzichteten sie auf die Ansprüche an miesto Chomutov, hrad Blathna, a dwuor Byczkowicze, sjich przislussnostmi („die Stadt Komotau, die Burg Platten, den Hof Byczkowicze mit Zubehör"). In seiner Vollmacht aber sprach der Deutschmeister immer von nostri ordinis opidum Comethaw,$^{78}$ obwohl der Orden den Ort bereits schon länger als 70 Jahre nicht mehr besaß.

Wie bereits erwähnt wurde auch Drobowitz, etwa bis zur Mitte des I 4. Jahrhunderts die wichtigste böhmische Kommende, I 4 I I Königsgut. Jost Quedenaw zufolge hielt diese ehemalige Kommende (Trogowitcz) im Frühling I 420 ein gewisser „Mitczk Tywetcza“, den wir als Mikeš/Mixo Divůček von Jemnischt (tsch. Jemniště) identifizieren können. Er war I 419-1 422 als Kuttenberger Münzmeister tätig, in sein Amt als bekannter Gegner der Hussiten durch König Sigismund nach dem Tod seines Bruders Wenzel eingesetzt. ${ }^{79}$ Anscheinend war es Sigismund, der Divůček Drobowitz mit den umliegenden Dörfern nahe Kuttenberg ausstattete. Auch Drobowitz blieb von den Einfällen der Hussitenheere nicht verschont. Davon berichtet das Schreiben eines anonymen Hussiten (vielleicht eines Mitgliedes des Geschlechts von Kunstadt/Kunštát) an seine Glaubensbrüder in Mähren. Dieses Schriftstück kann in die letzten Apriltage I 42 I datiert werden. Der Verfasser berichtet über die Einnahme von Deutschbrod, Kauřim, Kolin, Kuttenberg, Časlau und Nimburg sowie über das Niederbrennen der Klöster in Skalice, in Sedletz bei Kuttenberg und in Opatovice, wie auch über die Besetzung von Vilé-

77 NA Praha, ČG - GL, Nr. 461; Text in einer veralteten Edition gedruckt bei Millauer (wie Anm. 2), S. 191-196.

78 Millauer (wie Anm. 2), S. 194-195; vgl. Beránek, Beránková (wie Anm. 15), S. 50.

79 W. W. Tomek, Dějepis města Prahy, Bd. V, Praha 1881, S. 45; F. Palacký, Přehled současných nejvy̌šich di̊stojniku a úrednikü, doplnil J. Charvát, in: Dílo Frantiska Palackébo, Bd. I: Práce historické, ed. J. Charvát, Praha 1941, S. 349; Šmahel (wie Anm. 17), S. 907, 1038, 1063, 1068, $1110,1137,1165$. 
mov, Drobowitz und Sazau. Die Hussiten eroberten auch Burgen mit königlicher Besatzung, Lichtenburg (Lichnice) und Žleb (Žleby). ${ }^{80}$

Aus den folgenden Jahren sind Nachrichten zu Drobowitz nicht überliefert. Erst am 3. Oktober I 436 übergab Kaiser Sigismund Georg von Dauba auf Weissenburg (tsch. Vizmburk) die alten Briefe auf Žleb, Lichtenburg und Drobowitz, die an Johann Městecký von Opotschno (tsch. Opočno) ausgestellt worden waren, d. h. er überschrieb ihm die Pfandsumme, insgesamt 13000 Schock Groschen auf Drobowitz, die Burgen Žleb und Wildenstein (tsch. Vildštejn) und die Stadt Chotěboř (mittelhochdeutsch Kotbors). „Falls die preußischen Kreuzherren die Festung Drobowitz in Übereinstimmung mit dem Willen des Königs auszahlen wollten" (kdyžby křižovnici Pruští tvrz Drobovice vyplatiti chtéli s vuoli královskou), sollte von ihnen Georg 4000 Schock Groschen bekommen. ${ }^{81}$ Ein Jahr später, am 2 I. Oktober I 437, verschrieb Sigismund dem Georg von Dauba weitere I 000 Schock Groschen auf Drobowitz. Sigismund war von Georg gemahnt worden, er solle von Johann Městecký die Auszahlung die (königlichen) Schuldverschreibungen erlangen, welche Městecký die Vormundschaft der Waisenkinder des Johann von Neuhaus auf Teltsch (tsch. Telč) sichern sollten. Doch Georg erwarb dann weder die Vormundschaft über die Waisen noch einen entsprechenden Ersatz. ${ }^{82}$ Dies erklärt sich jedoch daraus, dass zum Pfandherrn von Drobowitz einige Zeit Johann Městecký von Opotschno geworden war, ein weiterer bedeutender Gegner der Hussiten.

Der Relation Wilhelm von Schönburg von 1459 zufolge besaß Drobowitz als Pfand im Wert von 4000 Schock Groschen ein gewisser Yetrzych Klumetzky, der niemand anderes als König Georgs treuer Parteiangehöriger Dietrich (tsch. Jetřich) von Janowitz (tsch. Janovice) auf (Hoch) Chlumetz (tsch. Vysoký Chlumec) war, nachmals I $465-1467$ oberster Landrichter. ${ }^{83}$

Als weiterer Herr von Drobowitz kommt I 487 Johann Špetle von Prudice vor, Herr auf Žleb, Dlouhá Ves und Tupadly. Er hatte seine Herrschaft von Dietrichs Sohn Johann erworben, einschließlich der Pfandschaft über Drobowitz. Johann Špetle verkaufte am I 2. August I 5 I 0 Drobowitz, das verödete Kloster und das Dorf, sowie die Dörfer Tupadly, Potěhy, Bratčice, Vinaře, Kozohlody, Přibyslavice und Zbudovice den Brüdern Peter und Prokop von Lukawetz (tsch. Lukavice). ${ }^{84}$

80 AČ III, S. 300-301, Nr. 21; vgl. Šmahel (wie Anm. 17), S. 1165-1166, zur Autorschaft des erwähnten Briefes ebd., S. 1174-1175.

81 Sedláček (wie Anm. 16), Nr. 1358, S. 187; AČ II, S. 176-177, Nr. 280.

82 Sedláček (wie Anm. 16), Nr. 1504, S. 206; AČ II, S. 177, Nr. 281.

83 Vgl. Palacký (wie Anm. 32), S. 359.

84 J. Hendrich, Drobovice, Výroční zpráva Musejního spolku „Včela Čáslavská“ za rok 1886-87 (1887), S. 24 
Das Zentrum des Gutes lag nicht mehr in der verödeten Kommende, sondern in dem festen Haus in der benachbarten Ortschaft Tupadly.

Ähnlich stellt sich das Schicksal weiterer Ordenskommenden auf dem Lande dar, Repín oder Miletein in Böhmen oder, die wohlhabendste Kommende, Austerlitz in Mähren. Kein einziges dieser Güter kam je zurück in den Besitz des Ordens.

Die Lage der Johanniter in Böhmen und Mähren war zwar anders, zeigte aber auch viele Gemeinsamkeiten mit dem Deutschen Orden. Vor dem Ausbruch der hussitischen Revolution wurden die Johanniter nicht von der Beschlagnahmungen ertragreicher Güter betroffen, hatten aber gleich anderen geistlichen Orden unter der wiederholten Erhebung der steigenden Sondersteuer (berna specialis) zu leiden. Eben wegen der Steuerschulden, die an den böhmischen König bezahlt werden mussten, verkauften der Landprior Heinrich von Neuhaus, der Komtur Zdeněk, der Prior Jakob und der Konvent der Prager Kommende bei der hl. Jungfrau am Ende der Brücke in der Kleinseite am 17. Juni 14 I 8 an Anna von Kolditz auf deren Lebenszeit, d. h. sie verpfändeten neun Dörfer in der Gegend von Aussig an der Elbe $^{85}$ für insgesamt 256 Schock Prager Groschen mit der Pflicht zur Landes-, d. h. allgemeinen Steuer von 23 Schock und 47 Groschen binnen zwei Wochen nach Ankündigung, und zwar an die Steuereinnehmer in Aussig beizutragen. Für jede um zwei Wochen verspätete Zahlung musste eine Geldstrafe von einem Schock bezahlt werden. ${ }^{86}$ Ähnlich, d. h. durch Verpfändung auf Lebenszeit, wurden vom Prager Prior und Konvent, wie aus der Zustimmung König Wenzels vom 9. Dezember I 4 I 3 hervorgeht, die Festung, der Hof und das Dorf (fortalicium, curiam allodialem et villam) Uhř́něves mit zugehörigen Dörfern (Kolovraty, Tehovec, Voděrádky, Krabošice, Zděbrady, Přestavlky, Lipany) an Anna, die Witwe des Jessko von Chlum, verkauft, wobei diese Güter aus dem Besitz des Templerordens kamen. $^{87}$

Eben der Prior Heinrich von Neuhaus, Mixo Divůček und weitere katholische Herren begegneten den Hussiten in einer der ersten, an sich nicht wichtigen Auseinandersetzungen auf dem Schlachtfeld, die aber umso geschickter von der hussitischen Propaganda ausgenutzt wurde. Von Neuhaus bezahlte seine Teilnahme in der Schlacht bei Sudomiersch (tsch. Sudoměř) am 25. März I 420 mit dem

\footnotetext{
85 Es handelte sich um die Dörfer Předlice mit dem Kirchenpatronat, Kliže, Újezd, Bánov, Užín, Varvažov, Habrovice, Radešín und Levín.

86 NA Praha, Archiv velkopřevorství maltézského (weiter: AVM), Listiny, Nr. 2321.

87 NA Praha, AVM, Listiny, Nr. 2313.
} 
Leben. Getroffen durch einen Armbrustpfeil in die Zehe, verstarb er nach ein paar Monaten wahrscheinlich an Wundbrand.$^{88}$ Nicht lange danach, am 8. Mai I 420 , wurde im Rahmen der nächsten Verwüstungswelle Prager Klöster und auf Anordnung von Hynek Krušina von Lichtenburg als Maßnahme gegen die katholische Besatzung auf der Prager Burg die Johanniterkommende bei hl. Jungfrau auf der Prager Kleinseite geplündert und stark beschädigt. Der Orden büßte damit seinen führenden und ältesten Sitz ein. Völlig verwüstet wurde die ganze Gegend auf der Kleinseite, einschließlich des weit entfernten Prämonstratenserklosters Strahow und des nähergelegenen Klosters der Augustinereremiten St. Thomas. Die Kleinseite war praktisch nicht mehr existent. ${ }^{89}$

Der Prior Heinrich von Neuhaus kaufte bereits zu Anfang seiner Amtsperiode ( 1402 ) recht weitblickend die zweite Hälfte der Burg und die Herrschaft Strakonitz (tsch. Strakonice). Die Johanniter gewannen dadurch einen konzentrierten Güterkomplex mit gut befestigter Burg, welche in Zukunft zum führenden katholischen Bollwerk nicht nur in Südböhmen avancierte. Nach der ersten Phase der Prager Bilderstürme im Herbst I 419 wurden anscheinend alle Kostbarkeiten sowie wichtige Urkunden des Priorats und der Prager Kommende eben nach Strakonitz gebracht. Ende April I 420 gelang es sogar nicht Johann Žižka, die Burg Strakonitz zu erobern; nur die nahegelegene kleine Stadt wurde damals völlig verbrannt. ${ }^{\circ}$ Trotzdem überstanden die Bewohner von Strakonitz die Zeit der Hussitenkriege ohne empfindliche Verluste. Auf die zugehörigen Dörfer konnte König Sigismund nicht zugreifen, denn sie fielen nicht in sein Stifterrecht; vielmehr hatten die Johanniter sie von dem Adelsgeschlecht der Bavor von Strakonitz erworben. Gefährdet waren somit vor allem zwei weitere größere Besitzkomplexe des Ordens, nämlich Böhmisch Aicha (tsch. Český Dub), eine kleine Stadt mit 38 Dörfern in Nordböhmen, und Manetin (tsch. Manětín), ebenfalls eine kleine Stadt mit 28 Dörfern in Westböhmen, ferner die weit im Lande verstreuten Dörfer der Prager Kommende.

Erste Verpfändungen des Besitzes der Johanniter nahm der König Sigismund am 28. Oktober 1420 in Angriff. Johann Chudoba von Ralsko auf Wartenberg

88 Übersichtlich Šmahel (wie Anm. 17), S. 1063-1065; zur Persönlichkeit Heinrichs von Neuhaus M. Svoboda, Jindřich z Hradce, prevor rádu johanitů, in: Historie '96. Studentská védecká konference Hradec Králové 1997, Hradec Králové 1997, S. 35-57. Über seiner Verletzung Staré letopisy české z rukopisu krížovnického, ed. F. Šimek, M. Kaňák, Praha 1959, S. 61: „Tu pan Jindřich křižovník postřelen v palec nožní a od té rány chřadl bliž k roku, až jest za to i hrdlo dal."

89 Vavrince z Březové Kronika (wie Anm. 17), S. 368; im breiteren Zusammenhang Šmahel (wie Anm. 17), S. 1080.

90 Vgl. Šmahel (wie Anm. 17), S. 1069-1070. 
verschrieb er außer Gütern anderer geistlicher Institutionen Dub cruciferorum ecclesie sancte Marie in pede pontis (,klášter Dub křrižovníkův Svatomářských“), ${ }^{1}$ also die Kommende und Herrschaft in Böhmisch Aicha, um I 794 Schock für Dienste und 3206 Schock alter Schulden. Ferner kamen Manětín an Bohuslav von Schwanberg um rooo Schock, an Parcifal und Lot von Prostiboř (von Vinařice) das Dorf des Prager Konvents Pochvalov mit zwei Dörfern des Raudnitzer Klosters der Augustinerchorherrn um 250 Schock, und zwar für den Schutz des Gutes und für Dienst mit 20 Pferden 26 Wochen lang bei der Verteidigung der Prager Burg, das Dorf Zdětín derselben Kommende mit weiteren Gütern der Kirche an Wenzel Myška von Hrádek, ${ }^{92}$ das Dorf Úhy, ein Dorf des Stifts Breunau (tsch. Břevnov) und die Einkünfte einer Veitspräbende an die Brüder Johann Firšic und Heinrich von Nabdín, ferner Dř́nov, Poštovice und Lešany mit einem Dorf der Prager Chorherrn um I 30 Schock und 72 Schock für frühere Dienste an Pavlík und Ulrich von Dvojice.93

Ein wenig überraschend wirkt das Vorgehen König Sigismunds im Spätsommer des Jahres I 422. In Nürnberg, wohin die Verhandlungen des ursprünglich nach Regensburg einberufenen Reichstags verlegt worden waren, erließ er am 23. August eine Reihe von gleichlautenden Urkunden, durch welche die früheren Verpfändungen von Gütern ausgewählter kirchlicher Institutionen in Böhmen und Mähren aufgehoben wurden. ${ }^{94}$ Unter diesen Institutionen wurde auch die domus sancte Marie Pragensis in pede pontis ordinis Johannitarum genannt, also die Prager Kommende, die höchstwahrscheinlich das ganze Johanniterpriorat bzw. dessen böhmischen und mährischen Teil (Ballei) vertrat. ${ }^{95}$ Der Widerruf der Verpfändungen stellte ein Entgegenkommen gegenüber der Kirche dar, die Sigismund als wichtigen und natürlichen Verbündeten im Kampf um den böhmischen Thron brauchte. Am Ende der Narratio seiner Urkunden über den Widerruf der

91 In Böhmen wurden die Johanniter im 15. Jahrhundert oft als „křížovníci svatomářšsti“, Marienkreuzherren oder Kreuzherren der hl. Jungfrau bezeichnet, nach ihrem Hauptsitz, der Prager Kommende bei hl. Jungfrau in Kleinseite. Es handelt sich also nicht um den Deutschorden.

92 Sedláček (wie Anm. 16), Nr. 1073, 1074, 1075, 1077 auf S. 154; AČ II, S. 177-176, Nr. 284.

93 Sedláček (wie Anm. 16), Nr. 938, S. 132; Nr. 944, S. 133. Zu den Verpfändungen des Eigentums des Prager Konvents siehe M. Svoboda, Pozemková držba pražské komendy johanitu a jeji sekvestrace v 15. století, in: Historie 1997. Celostátni studentská védecká konference, Brno 1998, S. 94-95; ders., Majetek rádu johanitů v Čechách v husitské dobè. Podil Zikmunda Lucemburského na likvidaci pozemkového majetku cirkve, Český časopis historický 103 (2005), S. 281-282.

94 Dazu am neuesten S. Bárta, Odvolání zástav statkủ cirkevnich instituci Zikmundem Lucemburským na obecném snèmu v Norimberku 23. srpna 1422, Časopis Matice moravské 133 (2014), S. 383-407.

95 SOA Třeboň, Historica Třeboň, sg. 239; Sedláček (wie Anm. 16), Nr. 1201, S. 167; vgl. Bárta (wie Anm. 47), S. 400. 
Verpfändung afectu geistlicher Institutionen gibt Sigismund selbst zu, solches Vorgehen sei sowohl hinsichtlich des kanonischen als auch des römischen Rechtes ungültig, und nennt er mögliche konkrete Schritte zur Restitution und zum Schutz des Klostereigentums. Die ältere Forschungsliteratur hat dies als Heuchelei Sigismunds gewertet und das Recht auf Verpfändung von Gütern geistlicher Institutionen wurde als Bestandteil des sogenannten Stifterrechts angesehen. Jüngst tauchte dagegen die Auffassung auf, direkte Verpfändungen Kloster- und Ordensgüter seien zu jeder Zeit ,unanständig " gewesen und hätten im Gegensatz zu allen zeitgenössischen Gewohnheiten gestanden (ausgenommen die Verpfändungen mit speziellem Grund, etwa zur Bezahlung der von den Klöstern geschuldeten Steuern)..$^{96}$

Keines der verpfändeten Güter wurde jedoch nach dem Erlass des Widerrufs durch Sigismund an die kirchlichen Institutionen zurückgegeben. In manchen Fällen wurden erneut Verpfändungen realisiert, wie im Falle von Manetin, obwohl wir hier besonderen Umständen begegnen. Bohuslav von Schwanberg, der Manetin als Pfand besaß, wurde Anfang I 42 I nach der Kapitulation seiner Burg Schwanberg von den Hussiten festgesetzt. Gefangengehalten in Př́běnice konvertierte er und wurde zu einem der hussitischen Hauptleute. ${ }^{97}$ Deswegen übergab Sigismund die Pfandschaft an Bohuslavs Bruder Hynek Krušina von Schwanberg, der ein Anhänger der königlichen Partei blieb. Zu Ofen (Buda) verlieh Sigismund am I 2. August I 425 Manetin mit der Herrschaft an Hynek Krušina um 700 Schock Groschen, mit denen er zum Aufkauf der Burg Schwanburg aus hussitischen Händen beisteuern wollte, um weitere 300 Schock für geschuldeten Sold und schließlich um 1000 Schock, für die er 100 Söldnerreiter auf seiner Burg halten sollte zu deren Verteidigung ,, und damit er ihnen jedweden Streit antut“, d. h. um gegen die Hussiten einen Partisanenkrieg zu führen. ${ }^{8}$ Manetin blieb in den Händen des Geschlechts von Schwanberg viele Jahrzehnte lang, bis I 560.99

Johann Chudoba von Ralsko besaß Böhmisch Aicha nur ein paar Jahre. Anfang Juli 1425 bezwang ein hussitisches Heer, bestehend aus der Besatzung von Nimburg und den Waisen sowie angeführt wahrscheinlich durch Johann Čapek von Sány, die Burg Michelsberg (tsch. Michalovice) und folglich auch die befe-

96 Bárta (wie Anm. 47), S. 384-387, 398-399. In Anm. 1 auf S. 383-384 führt der Verfasser übersichtlich die älteren Ansichten auf.

97 Šmahel (wie Anm. 17), S. 1142. Bohuslav von Schwanberg wurde oberster taboritischer Hauptmann, starb aber schon Ende November 1425 infolge seiner Verwundung bei der Eroberung von Retz in Österreich.

98 Sedláček (wie Anm. 16), Nr. 344, S. 190.

99 Vgl. J. Čechura, Kněkterým aspekti̛m právnich vtahů poddanskébo mèstečka Manètina k vrchnosti do poloviny 15. století, Právněhistorické studie 31 (1990), S. 73. 
stigte Kommende in Böhmisch Aicha, Weißwasser (tsch. Bělá pod Bezdězem), Niemes (tsch. Mimoň) und Deutsch Gabel (tsch. Jablonné). ${ }^{100}$ In der Literatur wird eine erneute Eroberung von Böhmisch Aicha durch die Waisen Anfang Juli I 427 angegeben; ${ }^{101}$ dabei handelt es sich jedoch anscheinend um eine Fehldatierung des Unternehmens von I 425. Wir wissen nicht, seit wann Böhmisch Aicha der bedeutende Hussitengegner Georg von Dauba und auf Weissenburg besaß, welcher hier seinen Amtmann Ulrich Močihub von Kralovice einsetzte. ${ }^{102}$ Dann jedoch tauchte wiederum Johann Čapek von Sány auf, der sich im Rahmen der Friedens- und Ausgleichsbemühungen nach der Schlacht bei Lipan vom 30. Mai I 434 Böhmisch Aicha gemeinsam mit der Burg Kreuzburg (Dub mèsto a kláster, Krucemburk hrad), und dem Zisterzienserkloster Hradischt (tsch. Hradiště) gegen 3000 Schock Groschen im Oktober I 436 von König Sigismund verschreiben ließ. ${ }^{103}$ Seine Eroberung aus den stürmischen Kriegszeiten wurde dadurch legalisiert. Wahrscheinlich nach dem Tod von Čapek (etwa I 452) ging die Herrschaft in den Besitz der Herren von Dauba über, ohne dass geklärt werden kann, wie. Es dürfte wiederum eine Form von Verpfändung in Frage kommen, einschlägige Aufzeichnungen sind aber nicht erhalten.

Die Eintragung von Böhmisch Aicha stand allerdings am Anfang vieler Verpfändungen von Kirchengütern, mit denen Sigismund seine Getreuen belohnte oder Schulden bezahlte, gegebenenfalls auch ehemalige hussitischen Hauptleute für sich gewinnen oder korrumpieren wollte, wie die Fälle des Jakoubek von Vrresovice und des eben genannten Jan Čapek zeigen. So hat der König im Laufe der Jahre I 436-I 437 außer Böhmisch Aicha, Ploschkowitz und Uhř́něves mit sechs Dörfern auch weitere I 5 bzw. I 6 Dörfer fremden Personen überschrieben, ${ }^{104}$ die ursprünglich zu den Gütern der Prager Kommende gezählt hatten. Dienten die Verpfändungen 1420-1422 vor allem zur Begleichung von Kriegskosten, bezweckten sie I 436-I 437 mehr die Stabilisierung des Landes und der Königsherrschaft. ${ }^{105}$ Zwischen 1453 und 1454 revidierte der Landesverwalter Georg von Podiebrad die Pfandschaften von Kron- und Kirchengütern, wobei deren Besitzer durch die Verpfändungsurkunden die Rechtmäßigkeit ihres Besitzes unter Beweis

100 Šmahel (wie Anm. 17), S. 1358.

${ }^{101}$ F. M. Bartoš, Husitská revoluce, Bd. II: Vláda bratrstev a jejípád 1426-1437 (České dějiny II. 8), Praha 1966, S. 32; Šmahel (wie Anm. 17), S. 1423.

102 NA Prag, AVM, Listiny, Nr. 2822.

103 Sedláček (wie Anm. 16), Nr. 1373, S. 189.

104 Sedláček (wie Anm. 16), Nr. 1334, 1344, 1345, 1373, 1381, 1395, 1405, 1407, 1410, 1491 , 1508, 1515, 1522. M. Svoboda, Majetek ŕádu johanitu (wie Anm. 46), S. 289, führt gerade 24 Dörfer des Prager Konvents an.

105 Vgl. Bárta (wie Anm. 47), S. 398-399. 
stellen mussten. Alle Verpfändungen des Johanniterbesitzes wurden in der Tat als rechtmäßig bestätigt. Die einzige Ausnahme stellten neun Dörfer bei Aussig an der Elbe dar, die nach dem Tode Anna von Kolditz', der Witwe Borssos IX. von Riesenburg, unrechtmäßig Johann von Wartenberg besetzt hatte. ${ }^{106}$ König Ladislaus Posthumus verlieh dann am I 2. März I 454 dem Prior der Johanniter Jodok von Rosenberg die Vollmacht zur Auszahlung der verpfändeten Güter seines Ordens und auch der Prager Propstei, die Jodok hielt. ${ }^{107}$

Etwas anders entwickelte sich die Lage in Mähren, wo das hussitische Zeitalter faktisch nur die Kommende in Altbrünn überdauerte, deren Komture dann häufig im Namen der ganzen Ordens im Lande auftraten. Die bedeutendste Kommende waren Orlowitz bei Wischau (tsch. Vyškov), wo die Johanniter eine Burg, die kleine Stadt Eiwanowitz in der Hanna (tsch. Ivanovice na Hané) und vier Dörfer besaßen. Ursprünglich gehörte der Kommende auch das Dorf Mutienitz (tsch. Mutěnice) in der wichtigen Weingegend bei Göding; im I 4. Jahrhundert wurde hier aber ein selbständiges Ordenshaus errichtet. König Sigismund besetzte, wahrscheinlich aus strategischen Gründen, Anfang der 2oer Jahre Orlowitz. Wohl um I 425 wurde die Ortschaft Haschek von Waldstein für 2600 Mark Groschen verpfändet. Haschek trat den Besitz für I 300 Mark an Nikolaus von Vojslavice ab, von dem es nach dem Zeugnis von I 445 die Johanniter zurückgekauft haben. In Jahre I 445 aber verpfändeten sie Orlowitz mit Zubehör dem Brünner Bürger Michael Kunigsfelder, seiner Frau und deren Schwiegersohn Stephan Lang, wobei der genannte Bürger bereits aus früherer Zeit einen Zins von 30 Mark aus der Sondersteuer besaß. Nach dem Tod von Kunigsfelder und Lang wurde zum Hauptinhaber der Pfandschaft der zweite Gemahl der Witwe von Lang, Hannus Ryssan, dem der Prior Jodok dies aufgrund der königlichen Genehmigung verpfändete. Die Herrschaft Orlowitz wurde mit weiteren Darlehen belastet. Schließlich ließ sie König Matthias Corvinus seinem Kanzler, dem Bischof von Großwardein Johann Filipec, für gewisse Summe, die dem Ordensprior übergeben wurde, am I 3. Januar I 483 in die Landtafel eintragen. ${ }^{108}$

Auch Mutienitz büßte der Orden ein. Das Dorf verpfändete König Sigismund am 25. August 1426 (unter seinem deutschen Namen „Kreuz“) einem seiner Befehlshaber, Čeněk von Mošnov. Im Jahre 1437 bestätigte er diese Verpfändung gemeinsam mit weiteren Burgen und Gütern im Südwestmähren. Die Johanniter

106 AČ II, S. 493-494; Svoboda, Majetek (wie Anm. 46), S. 295-297.

107 NA Praha, AVM, Listiny, Nr. 997; Sedláček (wie Anm. 16), S. 230.

108 Ausführlich beschreibt die Schicksale der Johannitergüter Orlowitz und Iwanowitz in der hussitischen und nachhussitischen Zeit L. Jan, Ivanovice na Hané, Orlovice a johanitský rád. (Príspèvek k poznáni struktury a ekonomiky rytiřrských duchounich rádí do konce 15. století), Časopis Matice moravské 111 (1992), S. 214-218. 
übergaben im Jahre 146I Mutienitz den Brüdern Nikolaus und Johann Bystřice von Ojnice. Später bemächtigte sich dieser Güter Johann Kuna von Kunstadt, der Herr des benachbarten Göding (tsch. Hodonín). Aufgrund weiterer Transaktionen gelangte das Dorf an Heinrich von Leipa und dann an dessen Sohn Johann, der mit dem damaligen Landprior Johann von Wartenberg und dem Prior des Prager Konvents vereinbarte, dass ihm Mutienitz für die Ersatzsumme von I $о \circ \circ$ Gulden in die Landtafel als Allodialbesitz eingetragen wurde, was in der Tat am 17. Mai I 537 geschah. Allerdings versuchte noch I 569 der Ordensprior Wenzel Hase von Hasenburg, das Dorf wiederzugewinnen, anscheinend aufgrund der Behauptung, dass vor zweiunddreißig Jahren lediglich die Verpfändung erhöht worden sei, was jedoch fehlschlug. ${ }^{109}$

Eine weitere bedeutende Kommende in Oberkaunitz (tsch. Horní Kounice) besetzte irgendwann in den Jahren I $422-1423$ der prohussitisch orientierte Johann Jevišovický von Kunstadt genannt Dürrteufel (Suchý čert); jedenfalls nannte er sich nach Oberkaunitz am 25. April I 424. ${ }^{10}$ Später war Oberkaunitz im Besitz seiner Söhne Boček und Hynek, wobei Boček hier seinen Ansitz hatte. ${ }^{111}$ Ihre Rechte legalisierten sie als Pfand anscheinend aufgrund der Verhandlungen mit dem Herrscher und vielleicht auch nach einer Vereinbarung mit den Johannitern. Im Jahre I 464 nämlich verklagte der Altbrünner Komtur Jakob den Boček von Kunstadt, dass er viele Jahre den Zins von 22 Mark aus allen Gütern nicht geleistet habe, die zu Oberkaunitz gehörten. ${ }^{12}$ Auf der Wende der 6oer und 7oer Jahre des I 5. Jahrhunderts wurde Oberkaunitz den Brüdern von Kunstadt konfisziert, da sie in Opposition gegen König Matthias Corvinus standen. Ihnen wurde Znaim zugeteilt als Ersatz für die Schäden, welche die königstreue Stadt erlitten hatte. Das wollte aber Boček nicht hinnehmen und die Znaimer musste die Feste Kaunitz, die einstige Kommende, im Sommer 1468 mit Waffengewalt erobern. ${ }^{13}$ Das Gut kam später an Boček von Kunstadt zurück, von dem es sein gleichnamiger Neffe erbte. ${ }^{114}$ Nach dessen Tode übernahmen, wir wissen nicht wie, das Oberkaunitzer Gut als Pfandschaft Beneš und sein Sohn Johann von Weitmühl (tsch. Weitmile).

109 Alles ausführlich beschrieben in L. Jan, V. Štěpánek, Mutěnice. Déjiny vinařské obce, Mutěnice 2002, S. 49-54, 72-80.

${ }^{110} \mathrm{~J}$. Šebánek, Archivy zrušených klästerů moravských a slezských, Bd. 1: Inventár pergamenů z let 1078-1471, Brno 1932, S. 260, Nr. 1246; vgl. M. Plaček, P. Futák, Páni z Kunštátu. Rod erbu vrchnich prubi na cestě k trionu, Praha 2006, S. 154.

111 Vgl. L. Jan, Ekonomické zázemí johanitské komendy v Hornich Kounicich, Jižní Morava 23 (1987), S. 89.

112 Libri citationum et sententiarum seu Knihy pỉhonné a nálezové (weiter: KP), Bd. IV, ed. V. Brandl, Brunae 1881, S. 115, Nr. 529.

113 Jan, Ekonomické (wie Anm. 64), S. 90; Plaček, Futák (wie Anm. 63), S. 157.

114 KP, Bd. V, Brunae 1891, S. 309, Nr. 243; S. 345, Nr. 459. 
Diesem Johann von Weitmühl schrieb König Wladislaus Oberkaunitz I 505 in die Landtafel als freien Besitz ein, denn die Pfandsummen waren derart gestiegen, dass es nicht möglich war, sie auszuzahlen. Der Eintrag besagte, dass die Herren von Weitmühl Kaunitz aufgrund von Verschreibungen der böhmischen Könige „od zákona kř́žovnického“ („von dem Kreuzherrnorden“) besaßen. ${ }^{115}$

Von ihren bedeutenden Besitzungen bekamen die Deutschordensritter so gut wie nichts zurück. Anfang des I 6. Jahrhunderts verfügten sie in den böhmischen Ländern nur noch über die Pfarrei in Pilsen und Deblin. Auch die Johanniter erlitten schwere Verluste. Ihre meisten Kommenden auf dem Lande gingen im Laufe des I 5. Jahrhunderts verloren. Außer manchen Kommenden in Ständen hielt sich nur die relativ starke Herrschaft Strakonitz, die im i 7. Jahrhundert zum Zentrum der Erneuerung der Ordensstrukturen wurde. Auch wenn die hussitischen Heere manche Kommenden und Pfarreien verwüsteten und verheerten, zu den eigentlichen Liquidatoren des Grundbesitzes beider geistlicher Ritterorden wurden die Könige Wenzel IV. und Sigismund. Mag an der rechtlichen Relevanz des sogenannten Stifterrechts gezweifelt werden, so war offenbar doch in der böhmischen Gesellschaft die „vorübergehende“ Verfügung über das Vermögen geistlicher Institutionen, welche die Herrscher begründet hatten, seitens eben dieser Herrscher in Notzeiten eine tief verwurzelte Alternative und galt als fester Bestandteil des Rechts im Lande.

\section{QUELLEN- UND LITERATURVERZEICHNIS}

Brandl, Vincentius. "Libri citationum et sententiarum seu Knihy půhonné a nálezové." Bd. 4. Brunae: Břeža, Winiker et soc., I $88 \mathrm{I}$.

Čelakovský, Jaromir., Friedrich, Gustav., edit. "Codex iuris municipalis regni Bohemiae. Privilegia regalium civitatum provincialium annorum I420-I 526." Praha: tiskem Národní Správy fy dr. Eduard Grégr a Syn, 1948.

Černá, Alena., Čornej, Petr. Klosová, Markéta., edit. "Staré letopisy české (texty nejstarší vrstvy)." Praha: Filosofia, 2003.

Emler, Joseph., edit. "Kronika starého kollegiata Pražského. Chronicon veteris collegiati Pragensis" In Fontes rerum Bohemicarum. Bd. 6,7. Praha: V komisi Dr. Grégr, I 893.

115 Moravské zemské desky 1480-1566. Kraj brněnský, Bd. 2, ed. T. Kalina, Praha 1950, S. 120, Buch. XVII, Nr. 224. 
Emler, Joseph., edit. "Libri confirmationum ad beneficia ecclesiastica Pragensem per archidiocesim” Bd. 7. Pragae: Historický spolek, I 886. Bd. 8-ı. Pragae: V komisi Dr. Grégr, I 889.

Ermisch, Hubert., edit. "Codex diplomaticus Saxoniae regiae." Bd. 2: Urkundenbuch des Stadt Chemnitz und ihrer Klöster. Leipzig: Giesecke \& Devrient, I 879.

"Fontes rerum Austriacarum." Bd. 2: Diplomataria et Acta. Wien: H. Böhlaus, I 860.

Goll, Jaroslav., edit. "Vavřince z Březové Kronika husitská." In Fontes rerum Bohemicarum. Bd. 5, 327-534. Praha: Spolek historický, I 893.

Joachim, Erich., Hubatsch, Walter., edit. "Regesta historico-diplomatica Ordinis S. Mariae Theutonicorum I I 98-I 5 I 5." Pars I., vol. I, Göttingen: Vandenhoeck \& Ruprecht, I948.

Kalina, Tomáš., edit. "Moravské zemské desky I 480-1 566 . Kraj brněnský." Bd. 2. Praha: Naḱl. Zemské banky pro Moravu a Slezsko, 1950.

Sedláček, August., edit. "Zbytky register králův římských a českých z let I 36I-I 480." Praha: Nákl. České akademie císaře Františka Josefa pro vědy, slovesnost a uměn, I 9 I 5.

Šimek, František., Kaňák, Miroslav., edit. "Staré letopisy české z rukopisu křížovnického." Praha: SNKLHU, 1959.

Strehlke, Ernst., edit. "Di Kronike von Pruzinlant des Nicolaus von Jeroschin." In Scriptores rerum Prussicarum. Die Geschichtsquellen der Preußischen Vorzeit bis zum Untergange der Ordensherrschaft, edited by Theodor Hirsch, Max Toeppen and Ernst Strehlke. Bd. I., 29 I-624. Leipzig: Von Hirzel, I 86 I.

Arnold, Udo. "Konrad von Feuchtwangen." In Udo Arnold. Zakon krzyżacki z Ziemi Świętej nad Battyk, 60-ror. Toruń: Wydawnictwo Naukowe UMK, 1996.

Bárta, Stanislav. "Odvolání zástav statků církevních institucí Zikmundem Lucemburským na obecném sněmu v Norimberku 23. srpna I 422." Časopis Matice moravské I 33 (2014): $383-407$.

Bartoš, František M. Husitská revoluce. Bd. 2. Praha: Nakl. Československé akademie věd, 1966.

Beránek, Karel., Beránková, Věra. "Část archivu chomutovské komendy řádu německých rytiríu ve Státním ústředním archivu v Praze.” In Facta probant homines.bornik prisspěvkỉ k životnimu jubileu prof. Dr. Zdeňky Hledikové, edited by Ivan Hlaváček and Jan Hrdina, 47-60. Praha: Scriptorum, 1998.

Čapský, Martin. "Fiskální vazby českomoravské bailie a velmistrovské komory řádu německých rytî́ru." Sbornik prací flozofické fakulty brnènské univerzity / Studia bistorica Facultatis philosophicae Universitatis Brunensis C 46 (1999): 67-77.

Čapský, Martin. "Miletínská komenda řádu německých rytî̌ů v době předhusitské ve světle účetních pramenů.” In Celostátni studentská védecká konference Historie 1997, edited by Jan Janák, 9-29. Brno: Matice moravská, 1998.

Čechura, Jaroslav. "K některým aspektům právních vtahů poddanského městečka Manětína k vrchnosti do poloviny I 5 . století." Právněhistorickéstudie 3 I ( 1990 ): 9-29.

Hemmerle, Josef. Die Deutschordens-Ballei Böhmen in ihren Rechnungsbüchern I382-I44I. Bonn: Wissenschaftliches Archiv, 1967. 
Hendrich, Jan. “Drobovice.” Výročni zpráva Musejního spolku „Vccela Č́slavská" za rok I 886-87 (1 887): i 8-32.

Jan, Libor. “Ekonomické zázemí johanitské komendy v Horních Kounicích.” Jižní Morava 23 (1987): 85-94.

Jan, Libor. "Ivanovice na Hané, Orlovice a johanitský raád." Časopis Matice moravské I I I (1992): 199-226.

Jan, Libor. "King Wenceslas and the Dissolution of the Bohemian Bailiwick of the Teutonic Knights." In Mendicants, Military Orders and Regionalism in Medieval Europe, edited by Jürgen Sarnowsky, 233-242. Aldershot: Routledge, I 999.

Jan, Libor. "Zkáza českomoravské bailie řádu německých rytíruon." Časopis Matice moravské I 7 (1 998): 383-39i.

Jan, Libor., Štěpánek, Václav. Mutěnice. Dějiny vinařské obce. Mutěnice: Obec Mutěnice, 2002. Jurošková, Lucie. "Hospodářské strategie českomoravské bailie řádu německých rytírư. Př́klad chomutovské komendy.” In Ústecký sbornik historický, I25-156. Ústí nad Labem: Muzeum města Ústí nad Labem, 2004.

Millauer, Maximilian. Der deutsche Ritterorden in Böhmen. Ein Beitrag zur Reichs- und Kirchengeschichte Böhmens. Praga: Haase, I 832.

Niess, Ulrich. "Konrad von Feuchtwangen." In Die Hochmeister des Deutschen Ordens I190-1994, edited by Udo Arnold. Marburg: Elwert, I 998.

Palacký, František. "Přehled současných nejvy̌ších důstojníků a úředníků." In Dílo Františka Palackého I. Práce historické, edited by Jaroslav Charvát. Praha: L. Mazáč, I 94 I.

Pauk, Marcin R. Dziatalność fundacyjna możnowladztwa czeskiego i jej uwarunkowania spoteczne (XI-XIII wiek). Kraków, Warszawa: Societas Vistulana, 2000.

Pauk, Marcin R. "Klasztor jako zaplecze ekonomiczne władzy królewskiej w państwie ostatních Przemyślidów." In Klasztor w państwie średniowiecznym i nowożytnym, edited by Marek Derwich and Anna Pobóg-Lenartowicz, 225-240. Wrocław, Opole, Warszawa: DiG, 2005.

Plaček, Miroslav. Futák, Peter. Páni z Kunštátu. Rod erbu vrchních prubů na cestě k trůnu. Praha: Nakladatelství Lidové noviny, 2006.

Rak, Petr. Chomutov I252-2002. Vybraná data ze 750 let historie mèsta. Chomutov: Albis international, 2002.

Šebánek, Jindřich. Archivy zrušených klásterů moravských a slezských. Bd. I (Inventár pergamenů z let 1078-147I). Brno: Nákládem Země Moravskoslezské, I 932.

Šmahel, František. Die Hussitische Revolution. Bd. 2. Hannover: Hahnsche Buchhandlung, 2002.

Svoboda, Miroslav, “Jindřich z Hradce, převor řádu johanitů.” In Historie 'g6. Studentská védecká konference Hradec Králové 1997, 35-57. Hradec Králové: Pedagogická fakulta VŠP, I 997

Svoboda, Miroslav. "Majetek řádu johanitů v Čechách v husitské době. Podíl Zikmunda Lucemburského na likvidaci pozemkového majetku církve." Český časopis historický I03 (2005): 269-3 I 2 . 
Svoboda, Miroslav. "Pozemková držba pražské komendy johanitů a její sekvestrace v i 5 . století.” In Historie 1997. Celostátní studentská vědecká konference, 85-104. Brno: Matice moravská, 1998.

Tomek, Wácslaw W. Déjepis mèsta Prahy. Bd. 5. Praha: W Kommissi u F. Riwnáče, I 88 I.

Tresp, Uwe. "Jan Calta z Kamenné Hory." In Comotovia 2oos. Sbornik príspèveki z konference vènované výroči 400 let vykoupeni Chomutova $z$ poddanstvi (I605-2005), edited by Petr Rak, 27-36. Chomutov: Město Chomutov, 2006, S.

Tresp, Uwe. Söldner aus Böhmen. Im Dienst deutscher Fürsten: Kriegsgeschäft und Heeresorganisation im Is Jahrbundert. Paderborn: Schöningh, 2004.

Voigt, Johannes. Geschichte der Ballei des Deutschen Ordens in Böhmen (Denkschriften der kaiserlichen Akademie der Wissenschaften. Phil.-hist. Klasse I2). Wien: Gerold, I 862 .

\section{ABstract \\ On the fate of the estates of the chivalric orders - Bohemia and Moravia after the Hussite wars}

The paper deals synoptically with the fate of the estates of the of the Order of the Teutonic Knights and the Order of Saint John at the time of the Hussite wars and the time, which immediately followed. Already in the first decades of the i 5 th century, the Order of Teutonic Knights had to pledge their commanderies of Miletín and Býčkovice to be able to pay the royal excise tax (berna specialis). However, the real blow for the order estates was the intervention of King Wenceslas IV in I 4 I I. After the Battle of Grunwald, the order owed the king a relatively high sum and attempted to acquire another loan from him, but Wenceslas IV rejected that and on the contrary had important commanderies seized. The author monitors primarily the fates of Chomutov and Drobovice in Bohemia and Slavkov in Moravia. Only in the case of Chomutov at the end of the i 5 th century did its new holder Beneš of Veitmile provide a certain compensation to the Order of the Teutonic Knights; in the other cases the properties were sequestered without compensation.

Also the Order of St John pledges some estates in the pre-Hussite period to acquire money for excise taxes (villages near Ústí nad Labem and Uhříněves). At the beginning of the battles with the Hussites, the Order of St John's estates were pledged by King Sigismund of Luxembourg. It was for example the relatively large order estate with its centre in Český Dub in North Bohemia or some villages of the Prague convent near castle Panna. Moravian estates were also pledged, for instance Orlovice, Mutěnice and Horní Kounice show the approach of the order, which tried to redeem the estates from pledges; although if it managed in some cases, it pledged them further itself. Despite that, the Order of St John managed to maintain an important order estate with its main residence in Strakonice in South Bohemia, which became a significant anti-Hussite centre. Although the Hussites destroyed many estates, the real liquidators of the order economic bases were Kings Wenceslas IV and Sigismund. 